\title{
Biomechanical evaluation of a Personalized External Aortic Root Support applied in the Ross procedure
}

\author{
Julie Vastmans ${ }^{1}$, Heleen Fehervary ${ }^{1}$, Peter Verbrugghe ${ }^{2}$, Tom Verbelen ${ }^{2}$, \\ Emma Vanderveken ${ }^{2}$, Jos Vander Sloten ${ }^{1}$, Tom Treasure ${ }^{3}$, Filip Rega ${ }^{2}$, and \\ Nele Famaey ${ }^{1}$ \\ 1. Biomechanics section, $K U$ Leuven, Leuven, Belgium \\ 2. Centre of Experimental Cardiac Surgery, KU Leuven, Leuven, Belgium \\ 3. Clinical Operational Research Unit, UCL, London, UK
}

\begin{abstract}
A commonly heard concern in the Ross procedure, where a diseased aortic valve is replaced by the patient's own pulmonary valve, is the possibility of pulmonary autograft dilatation. We performed a biomechanical investigation of the use of a personalized external aortic root support or exostent as a possibility for supporting the autograft.

In ten sheep a short length of pulmonary artery was interposed in the descending aorta, serving as a simplified version of the Ross procedure. In seven of these cases, the autograft was supported by an external mesh or so-called exostent. Three sheep served as control, of which one was excluded from the mechanical testing. The sheep were sacrificed six months after the procedure. Samples of the relevant tissues were obtained for subsequent mechanical testing: normal aorta, normal pulmonary artery, aorta with exostent, pulmonary artery with exostent, and pulmonary artery in aortic position for six months. After mechanical testing, the material parameters of the Gasser-Ogden-Holzapfel model were determined for the different tissue types.

Stress-strain curves of the different tissue types show significantly different mechanical behavior. At baseline, stress-strain curves of the pulmonary artery are lower than aortic stress-strain curves, but at the strain levels at which the collagen fibers are recruited, the pulmonary artery behaves stiffer than the aorta. After being in aortic position for six months, the pulmonary artery tends to-
\end{abstract}


wards aorta-like behavior, indicating that growth and remodeling processes have taken place. When adding an exostent around the pulmonary autograft, the mechanical behavior of the composite artery (exostent + artery) differs from the artery alone, the non-linearity being more evident in the former.

Keywords: arterial tissue, exostent, constitutive modeling, planar biaxial testing

\section{Introduction}

Patients suffering from aortic valve disease can be treated by replacing their aortic valve with their own pulmonary valve, i.e. a pulmonary autograft. This procedure, known as the Ross procedure, has several advantages compared to replacement with a mechanical valve, such as better hemodynamic performance, no need for lifelong anticoagulant therapy, and the natural increase of autograft size in children [1]. Despite these advantages, possible dilatation of the autograft limits the use of this treatment 2. Freedom from autograft reoperation in the German-Dutch Ross registry was $89.6 \%$ after ten years [3].

Schoof et al. demonstrated the growth and dilatation of the pulmonary autograft in growing pigs, when replacing a length of the ascending aorta with an interposition pulmonary artery. They found that the increase in size of the pulmonary autograft is partly caused by normal growth and partly by dilatation. The authors believe that the main dilatation of the pulmonary autograft occurs at the moment the pulmonary autograft is loaded with aortic pressure. Despite the growth and dilatation, the pulmonary autograft wall still showed pulmonary characteristics both micro- and macroscopically after implantation in aortic position [4.

However, in another study by the same authors on the histological evaluation of human pulmonary autograft explants, they discovered that the autograft wall showed an increase in collagen content and a reduction and fragmentation of elastin, corresponding to severe aneurysmal degeneration [5].

Carr-White et al. compared human pulmonary artery wall to the normal aortic 
wall, noticing that the aorta is both stiffer and stronger. Additionally, they evaluated a pulmonary autograft that had been implanted for four months in a 14 year old patient, and described an increase in stiffness for this autograft, compared to pulmonary tissue [7].

When comparing the mechanical behavior of non-diseased human pulmonary and aortic roots, Azadani et al. found that the pulmonary artery is significantly stiffer than the aorta at systemic pressures 8 .

Mookhoek et al. had the opportunity to mechanically evaluate dilated pulmonary autografts of 10 patients who underwent the Ross operation and discovered that the autografts were significantly more compliant than the native aortic roots [9. In a subsequent paper by the same authors, they also noticed that pulmonary autografts are less stiff than the normal pulmonary roots [10]. To avoid dilatation of the pulmonary autograft when subjecting the pulmonary artery wall to systemic pressures, several types of reinforcements are suggested. Ungerleider et al. described a technique in which they place the pulmonary autograft in a Dacron graft prior to implantation in aortic position 2. Both Carrel et al. and Gebauer et al. proposed a similar technique, but instead of a Dacron graft, they used the sinus of the Valsalva graft [11, 12]. A case study by Kollar et al. reports the use of a Gore-Tex wrapping around the pulmonary autograft [13]. However, all these reinforcements are significantly stiffer than the native aorta and do not provide sufficient vascular compliance. Therefore, Nappi et al. proposed a resorbable reinforcement to strengthen the pulmonary autograft, which they evaluated in an ovine model [14, 15, 16, 17, 18.

Recently, a new technique was developed to reinforce the dilating aortic root in Marfan patients, i.e. a personalized external aortic root support (PEARS), as an alternative for the total root replacement or valve-sparing root replacement therapy. The PEARS is an external wrapping, which is tailored to the patientspecific geometry of the aortic root. Based on a CT or MRI of the aortic root of the patient, a replica of the patient's geometry is made by additive manufacturing. A polyethylene terephtalate mesh with a pore size of $0.7 \mathrm{~mm}$ is then crimped around this replica. Next, this PEARS is surgically placed around the 
patient's dilated aortic root [19, 20, 21]. The initial results of this less invasive treatment option for Marfan patients are promising [19, 20]. The inventors claim that this method, as opposed to wrapping of aneurysms with rigid woven grafts, results in the incorporation of the soft pliant mesh in the outer layer of the aorta [20]. This claim was confirmed after an autopsy on a patient, deceased 4.5 years after he received a PEARS due to unrelated circumstances, where the incorporation of the mesh was histologically shown. Moreover, the aortic root of this Marfan patient showed normal histology, instead of the expected cardiovascular manifestations (medial degeneration with fragmentation of elastic fibers and smooth muscle cell nuclei loss) [21].

The mechanical performance of the PEARS mesh was studied in sheep, of which the common carotid artery was enclosed in a mesh, made of the same material as the PEARS. Four to six months after implantation, the sheep were sacrificed and both meshed and normal portions of the carotid artery were analyzed mechanically and histologically. Again, incorporation of the mesh in the outer arterial wall was confirmed, and the histological architecture of the arterial wall preserved. Based on uniaxial tensile tests, a significant increase in both stiffness and tensile strength of the supported segments with respect to the normal carotid artery was reported [22].

In a more recent paper, Van Hoof et al. histologically evaluated the PEARS material, after it had been placed around the abdominal aorta of three sheep for a year, and compared it to the fabric used in the common vascular graft Gelweave. The PEARS material caused less disturbance to the native aortic wall compared to the material of the common vascular graft [23].

The above studies strongly suggest PEARS to be a promising method to reinforce the pulmonary autograft in the Ross procedure. To evaluate this hypothesis, this paper investigates the use of PEARS material in a simplified version of the Ross procedure in sheep. In the next sections, the surgical procedure and the mechanical characterization methodology are presented, after which the obtained results are described and discussed. 


\section{Materials and Methods}

\subsection{Surgical Procedure}

A simplified version of the Ross procedure was performed on thirteen Lovenaar sheep: part of the thoracic aorta descendens was replaced by part of the truncus pulmonalis. In ten sheep an exostent was positioned around the pulmonary autograft. The exostent, made of a polyethylene terephtalate mesh with a pore size of $0.7 \mathrm{~mm}$, was loosely fitted around the pulmonary autograft during surgery. The three remaining sheep served as control sheep. The sheep were sacrificed after an average of 28.4 weeks. Three sheep with the exostent died during surgery and were excluded. One of the control sheep did not have sufficient tissue harvested for mechanical testing and was excluded from mechanical testing. However, slices of the different tissues of this control sheep were obtained and examined microscopically. Before sacrifice, the diameter of the pulmonary artery, and the diameter of the aorta were measured on a CT scan. After sacrifice, the following types of tissues were harvested: normal aorta (A), reinforced aorta (AW), and reinforced pulmonary artery in aortic position (PW). In the control sheep, normal aorta $\left(\mathrm{A}^{c}\right)$, normal pulmonary artery $\left(\mathrm{P}^{c}\right)$, and pulmonary tissue in aortic position $\left(\mathrm{P}_{A}^{c}\right)$ were harvested. An overview of the harvested tissue types is shown in figure 1. Table 1 summarizes the details of all sheep. After removing the different tissue types, the tissues were frozen either in a physiological PBS solution or in a physiological $\mathrm{NaCl}$ solution, and stored at $-80^{\circ} \mathrm{C}$.

All experiments were approved by the Animal Ethics Committee of the KU Leuven (P053/2013).

\subsection{Experimental protocol}

First, the tissue obtained from the surgical procedure was divided into different samples. Next, sample preparation was performed including thickness measurements and marker attachment. Subsequently, the sample was mounted

in a biaxial tensile testing device and mechanically loaded. The different steps are summarized in figure 2 and detailed below. 


\subsubsection{Sample preparation}

Overnight, the tissues were thawed in a refrigerator at $4^{\circ} \mathrm{C}$. After thawing, the tissue was divided into square samples of $8 \mathrm{~mm} \times 8 \mathrm{~mm}$ for planar biaxial tests. The samples' edges were aligned with the circumferential and longitudinal direction of the vessel.

The thickness of each sample was obtained from an image in which the sample was placed between two metal plates of known thickness.

Small fragments of surgical suture wire served as markers. They were glued in the center region of the sample, where the stresses and strains are considered to be most homogeneous 24 . Four markers were placed at the corners of a square, and a fifth marker was placed in the center of this square.

\subsubsection{Planar biaxial tensile test}

The samples were mounted in a BioTester device (CellScale, Waterloo, Canada) by means of four BioRakes. Each BioRake consists of 5 pins spaced by $1 \mathrm{~mm}$, with a diameter of $300 \mu \mathrm{m}$ and a puncture length of $3 \mathrm{~mm}$. The BioTester has four actuators, which can be actuated independently, and two $23 \mathrm{~N}$ loadcells (with an accuracy of $0.2 \%$ of the full scale). A CCD camera (resolution 1280 pixels x 960 pixels) registered the sample as it deforms. Both the images and force measurements were taken at a sampling rate of $30 \mathrm{~Hz}$.

During the test, the sample was submerged into $0.9 \% \mathrm{NaCl}$ solution at $37^{\circ} \mathrm{C}$. Two types of protocols were used, which were displacement- or force-controlled. In the former, the displacement was imposed as a stretch [\%] of the rakes' position. The latter imposed a force on the sample. Table 2 gives the differences between the two protocols.

The physiological levels were determined using data from literature and Laplace's law. According to Bia et al., the mean systolic blood pressure in sheep is $96 \mathrm{mmHg}$ with a corresponding aortic diameter of $15.7 \mathrm{~mm}$. During diastole, a blood pressure of $74.8 \mathrm{mmHg}$ and a diameter of $14.7 \mathrm{~mm}$ is reached 25. Laplace's law $\left(\sigma_{c i r c}=\operatorname{Pr} / t\right)$ allowed us to roughly estimate the circumfer- 
ential stresses present in the arterial wall under physiological conditions. Taking into account the width of the loaded sample i.e. $W=6 \mathrm{~mm}$, the stress was converted to force as $F=\sigma_{\text {circ }} W t$. This resulted in a physiological force around $600 \mathrm{mN}$ in the circumferential direction during systole. The physiological strain was estimated as: $\epsilon=\left(D_{\text {sys }}-D_{\text {dia }}\right) / D_{\text {dia }}$ and equaled $\epsilon=6.8 \%$. The loading rate in case of the force-controlled protocol was $0.3 \mathrm{~N} / \mathrm{s}$, and the loading rate for the displacement-controlled protocol was $3.4 \% / s[26$. These roughly estimated physiological levels, which do not account for residual stresses, were used in the testing protocols.

All protocols started with a set of 10 preconditioning cycles which were performed at half of the estimated physiological level of the displacement or the force, respectively. After the preconditioning cycles, loading steps were imposed on the sample as a multitude of the physiological level calculated above. To probe the tissue's anisotropy, three different ratios of loads in the $\mathrm{x}$ - and y-direction were imposed per loading step: $L_{x}: L_{y}=1: 1,1: 0.5,0.5: 1$. In each ratio, the stretch-recover cycle was repeated five times. The final stretch step of each ratio of the last complete loading step was used for further analysis. In the first protocol, the sample was prestretched up to a load of $70 \mathrm{mN}$, at the start of every new set of five stretch cycles. In the second protocol, the same prestretch was imposed before every stretch cycle.

Figure 3 visualizes the forces obtained from the biaxial testing device in the circumferential and longitudinal direction. The deformation of the sample was calculated based on the position of the markers.

\subsection{Microstructural evaluation}

A basic histology is performed on a normal aorta (A) and pulmonary artery $\left(\mathrm{P}^{c}\right)$, a pulmonary artery in aortic position $\left(\mathrm{P}_{A}^{c}\right)$ (both from the same sheep) and a pulmonary artery in aortic position with exostent (PW). After fixation in paraformaldehyde and dehydradation, the samples were fixed in paraffin. Cross-sections were stained with Elastica van Gieson stains and visualized with

a Zeiss Axioplan 2 microscope and Axiocam MRc5 camera. The thickness was 
measured at five different locations on the cross-section. For a more extensive histological evaluation, the interested reader is referred to Vanderveken et al. [27.

\subsection{Constitutive modeling}

The GOH model [28] is a well-known constitutive law which describes the mechanical response of arterial tissue. Two layers are considered: the media and adventitia. Since the intima's influence is negligible in the determination of solid mechanical properties, this layer is not taken into account [29].

The adventitia and the media are described as a fiber-reinforced material, consisting of a non-collagenous matrix and collagenous fibers. Ideally, both arterial layers are modeled with the same form of the strain-energy density function (SEDF) with different material parameters for each layer. However in this study, no distinction between the different layers was made when testing the samples. Moreover, one biaxial test does not suffice for characterizing both layers simultaneously [30]. Therefore, one SEDF was used for the complete tissue. The SEDF is divided into a part modeling isotropic behavior and a part modeling anisotropic behavior:

$$
\Psi\left(\boldsymbol{C}, \boldsymbol{a}_{01}, \boldsymbol{a}_{02}\right)=\Psi_{i s o}(\boldsymbol{C})+\Psi_{\text {aniso }}\left(\boldsymbol{C}, \boldsymbol{a}_{01}, \boldsymbol{a}_{02}\right) .
$$

In this equation the vectors $\boldsymbol{a}_{01}$ and $\boldsymbol{a}_{02}$ correspond to the directions of the collagen fibers, and $\boldsymbol{C}=\boldsymbol{F}^{T} \boldsymbol{F}$ is the right Cauchy-Green tensor, where $\boldsymbol{F}$ symbolizes the deformation gradient [28, 29].

The isotropic part, associated with the mechanical response of the elastin matrix, is represented using the classic Neo-Hookean model, as $\Psi_{i s o}\left(\mathrm{I}_{1}\right)=C_{10}\left(\mathrm{I}_{1}-\right.$ 3 ), with $C_{10}$ a stress-like parameter, representing the stiffness of the matrix, and $\mathrm{I}_{1}$ the first invariant of the right Cauchy-Green tensor.

The anisotropic part models the response of the collagen fibers as

$$
\Psi_{\text {aniso }}=\frac{k_{1}}{2 k_{2}} \sum_{i=4,6}\left\{\exp \left[k_{2}\left(\kappa \mathrm{I}_{1}+(1-3 \kappa) \mathrm{I}_{\mathrm{i}}-1\right)^{2}\right]-1\right\},
$$

where $I_{4}$ and $I_{6}$ correspond to the fourth and sixth invariant of the right CauchyGreen tensor $\boldsymbol{C}: \mathrm{I}_{4}=\boldsymbol{C}: \boldsymbol{a}_{01} \otimes \boldsymbol{a}_{01}$ and $\mathrm{I}_{6}=\boldsymbol{C}: \boldsymbol{a}_{02} \otimes \boldsymbol{a}_{02}$. By assuming that 
the two fiber families are symmetrically oriented and that $F_{12}=F_{21}$, the fourth and sixth invariant become equal, since

$$
\boldsymbol{a}_{01}=\left[\begin{array}{c}
\sin \alpha \\
\cos \alpha \\
0
\end{array}\right], \boldsymbol{a}_{02}=\left[\begin{array}{c}
-\sin \alpha \\
\cos \alpha \\
0
\end{array}\right],
$$

where $\alpha$ expresses the angle between the collagen fibers and the longitudinal direction, i.e. when $\alpha=0$, the fibers are aligned along the longitudinal direction. $k_{1}$ relates to the stiffness of the fibers, while $k_{2}$ is linked to the nonlinear behavior of the tissue. Parameter $\kappa$ includes the effect of dispersion of the collagen fibers and expresses the degree of anisotropy in the arterial layer [28, 29].

\subsection{Parameter fitting}

To determine the material parameters, an objective function expressing the difference between the experimentally measured forces $\boldsymbol{R} \boldsymbol{F}^{\text {exp }}$, and the forces calculated based on the GOH model $\boldsymbol{R F}^{\text {mod }}$ in both directions, is minimized as

$$
\left(\boldsymbol{R}_{11}^{\text {mod }}-\boldsymbol{R}_{11}^{\text {exp }}\right)^{2}+\left(\boldsymbol{R}_{22}^{\text {mod }}-\boldsymbol{R}_{22}^{\text {exp }}\right)^{2} .
$$

The experimentally measured forces $\boldsymbol{R F}^{\text {exp }}$ followed directly from the experiment. The modeled forces $\boldsymbol{R F}^{\text {mod }}$ were calculated based on the deformation gradient measured in the experiment and the SEDF explained above.

Taking the coordinates of the four outer markers, an average circumferential $\lambda_{11}$ and longitudinal $\lambda_{22}$ stretch were calculated. Using the incompressibility assumption, i.e. $\operatorname{det}(\boldsymbol{F})=1$, and assuming no shear due to the alignment of the material axes with the test axes, the deformation gradient $\boldsymbol{F}$ becomes

$$
\boldsymbol{F}=\left[\begin{array}{ccc}
\lambda_{11} & 0 & 0 \\
0 & \lambda_{22} & 0 \\
0 & 0 & \frac{1}{\lambda_{11} \lambda_{22}}
\end{array}\right]
$$

Subsequently, the second Piola-Kirchhoff stress $\boldsymbol{S}_{\text {mod }}$ was calculated as

$$
\boldsymbol{S}_{\text {mod }}=-\mathrm{p} \boldsymbol{C}^{-1}+2 \frac{\partial \Psi\left(\boldsymbol{C}^{-1}\right)}{\partial \boldsymbol{C}} 29 .
$$


Next, the second Piola-Kirchhoff stress $\boldsymbol{S}_{\text {mod }}$ was multiplied with the deformation gradient $\boldsymbol{F}$, resulting in the first Piola-Kirchhoff stress $\boldsymbol{P}_{\text {mod }}$. Finally, the modeled reaction forces were determined by multiplying the first Piola-Kirchhoff stress with the undeformed area $A$, i.e. the initial distance between the rakes and the thickness of the sample.

The above calculations and the optimization procedure were done in Matlab 2015a, and the optimization procedure used to minimize the objective function was performed with $C a s A D i$, a freely available tool for nonlinear optimization [31. The function multistart in Matlab 2015a was used, which allowed us to execute the optimization procedure starting from 10 different parameter sets. The ranges for the different parameters are given in table 3 .

The material parameters are reported as a set of parameters for each specific sample, with the corresponding coefficient of determination $\mathrm{R}^{2}$. No mean parameter set was calculated for the tissue types, since averaging is a linear operation, whereas the constitutive model is nonlinear. Robertson et al. showed that for nonlinear constitutive models, average coefficients often do not represent average behavior 32 .

\section{Results}

During surgery, the immediate dilatation of the pulmonary autograft was apparent, as shown in figure 4. Six months after surgery, the maximal diameter of the native pulmonary artery, the pulmonary autograft and the aorta proximal and distal were determined based on the CT scan, and can be found in Table 4 Figure 5 shows microscopy images of the healthy aorta and pulmonary artery, the pulmonary autograft and the pulmonary autograft with wrapping after Elastica van Glieson staining. The first three pictures are taken from the same control sheep (sheep 0321). The third picture is taken from a sheep with the exostent (sheep 0434). The measured thicknesses on the microscopy slice are $1.90 \mathrm{~mm} \pm 0.11 \mathrm{~mm}$ for the aorta, $1.07 \mathrm{~mm} \pm 0.05 \mathrm{~mm}$ for the normal pulmonary artery, $1.06 \mathrm{~mm} \pm 0.18 \mathrm{~mm}$ for the pulmonary autograft, and $1.13 \mathrm{~mm} \pm 0.23 \mathrm{~mm}$ 
for the reinforced pulmonary autograft.

The different parameter sets for each of the samples are given in Appendix in tables 5 to 13 .

Figure 6 visualizes boxplots of the thicknesses and the material parameters $C_{10}$, $k_{1}$, and $k_{2}$. No boxplots were made for the structural parameters $\alpha$ and $\kappa$ since they often reach their limiting values in the fitting procedure. Due to the limited number of sheep, no statistical tests were performed.

The first Piola-Kirchhoff stress was plotted for all samples in figures 7 and 8 with respect to the stretch, both in circumferential and longitudinal direction. Figure 7 pertains to the samples of the two control sheep, whereas figure 8 shows the curves of the samples of the seven sheep with exostent.

\section{Discussion}

In total, five different tissue types can be distinguished: normal aorta ( $A$ and $\left.A^{c}\right)$, normal pulmonary $\left(P^{c}\right)$, aorta with exostent $(A W)$, pulmonary artery with exostent $(P W)$, and pulmonary in aorta position $\left(P_{A}^{c}\right)$. The discussion is divided into three parts, followed by a paragraph reviewing the study limitations and future work. First, we compare the normal or baseline behaviors of the pulmonary artery and aorta. The second part discusses the effect of the Ross procedure on the mechanical behavior of the pulmonary artery. Thirdly, the influence of the exostent is discussed.

\subsection{Baseline behavior}

Looking at figures 7 and 8 , one can clearly distinguish the different stressstrain curves pertaining to a specific tissue type.

On a microscopic level, the differences in medial thickness, structure and composition between both arteries become apparent soon after birth [33]. Figure 5 confirms these differences between normal aorta and normal pulmonary artery. When comparing normal aortic behavior and pulmonary artery mechanical behavior, one can see in figure 7 that the normal pulmonary artery stiffens 
at lower stretch levels than the normal aorta. This stiffening effect is quantified by the $k_{2}$ parameter in the material model. As can be seen in the corresponding boxplot (figure 6), this parameter appears to be higher in the pulmonary artery samples than in the normal aortic samples. Additionally, a lower initial slope of the stress-strain curves of the pulmonary arteries can be noticed when comparing it with aortic stress-strain curves.

Contrary to our results, Carr-White et al. [7 divided the stress-strain curves of pulmonary artery and aortic samples in a low and high stiffness region, and found that for both regions the aorta behaved stiffer than the pulmonary artery. However, the authors performed uniaxial tests in the circumferential direction on human tissue from patients undergoing autograft surgery, with ages ranging from 10 to 59 years as opposed to our biaxially tested samples of healthy, young sheep. Azadani et al. 8] performed experiments similar to the ones performed in this paper, and evaluated the stiffness in the systemic region for human pulmonary artery tissue and human aortic tissue of patients with a mean age of 50 years. Theydiscovered that pulmonary artery tissue behaves stiffer under systemic pressure. A similar conclusion can not be drawn for the young, ovine samples of this paper, since in the toe region, the stress-strain curves of aortic samples have a higher slope, whereas in the stiffening part, neither the aorta nor pulmonary artery appear to behave stiffer than the other.

\subsection{Effect of the Ross procedure}

Table 4 shows that the diameter of the pulmonary autograft is larger than the diameter of the normal pulmonary artery and the diameter of the proximal and distal aorta. This difference in size is more outspoken in the three control sheep than in the sheep with the exostent. However, to obtain statistical significance, more sheep and more data at different time points is needed.

The difference in mechanical behavior between the aorta and the pulmonary artery is visible in figure 7 and becomes relevant when performing the Ross procedure, since loading the pulmonary artery with systemic pressure leads to different stresses in the pulmonary wall compared to loading it with pulmonary 
pressures, or compared to normal aorta. Consequently, a disruption in the homeostatic state of the pulmonary artery occurs, triggering growth and remodeling reactions.

This assumption of remodelling is supported by figure 7 , showing that when the pulmonary artery has been in aorta position for six months, its mechanical behavior leans more to aortic behavior. Figure 5 also shows signs of remodelling. Subfigure $\mathrm{P}_{A}^{c}$ shows an increase in smooth muscle cells, causing wall thickening in the autograft compared to the pulmonary artery. However, this is a local effect, as the average thickness of the pulmonary autograft $(1.06 \mathrm{~mm} \pm 0.18 \mathrm{~mm})$ has not increased w.r.t. the pulmonary artery $(1.07 \mathrm{~mm} \pm 0.18 \mathrm{~mm})$, only the standard deviation has. The reduction and fragmentation of elastin, as found by [5] is not apparent in the pulmonary autograft.

This is contradictory to what Schoof et al. found, who discovered no microor macroscopical evidence for remodeling [4. Moreover, Mookhoek et al. mechanically evaluated dilated pulmonary autografts of ten patients and compared them to the native aortic root. They found that the autografts were significantly more compliant than the native root. The authors postulated that this decrease in vascular stiffness resulted from remodeling, and that, in this patient group, the autografts failed to remodel to represent native aortic roots at systemic pressures [9. In a follow-up paper, they compared the autografts with normal pulmonary arteries and the autografts appeared to be less stiff [10].

Contrarily, our results suggest that the pulmonary autograft starts to behave more aorta-like when positioned in aortic position. However, this discrepancy might result from the fact that Mookhoek et al. tested dilated pulmonary autografts, which failed to remodel [9, 10, whereas our samples appear to have remodeled.

\subsection{Effect of exostent}

Adding an external exostent changes the mechanical behavior of the composite (artery + exostent). Possibly, it can therefore bring the stresses in the arterial wall closer to their homeostatic value, diminishing the occurrence of 
growth and remodeling reactions. Figure5 shows that the elastin is compressed underneath the wrapping, as was also found by [23]. Placing the wrapping around the pulmonary artery (right), causes atrophy to the smooth muscle cells resulting in more densely packed elastin. The thickness of the pulmonary artery is decreased, but the addition of the wrapping and the fibrotic reaction results in an overall thickness that has not changed dramatically.

As shown in figure 8 , the samples with exostent material tend to stiffen sooner and more severely compared to the unreinforced samples. A slight increase in the $k_{2}$ parameter of the wrapped aortic samples compared to the normal aortic samples supports this observation. Comparing the pulmonary samples to the wrapped pulmonary samples, one can see that the initial slope of the curve is steeper in the exostent samples than in the normal pulmonary samples. An increase in stiffness was also found by Verbrugghe et al. 22,

\subsection{Study Limitations and Future Work}

A few remarks need to be made with respect to the surgical procedure. Firstly, the number of sheep is limited, especially the number of control sheep. In addition to the limited number of control sheep, the sheep are young and have a different remodeling potential compared to mature humans. In future experiments, more control sheep should be evaluated to be able to draw significant conclusions regarding growth and remodeling. Thirdly, the initial radius of the pulmonary autograft and its imposed axial prestretch are not measured. These limitations should be taken into account in future work. Mismatches in the initial radius of the pulmonary autograft and the host section of the aorta could have hemodynamic implications, which can influence the remodelling. Therefore, in future studies, the number of control animals should be increased and clinical images quantifying the geometry and flow should be taken postoperatively and before sacrifice.

In a Ross procedure, the aortic valve is replaced with the pulmonary valve, along with a portion of the pulmonary artery. In this paper, only a segment of the 
aorta is replaced with the pulmonary artery due to anatomical constraints of the ovine model (e.g. the shortness of the aorta and pulmonary trunk). Nappi et al. encountered similar limitations in their study [16]. Due to this simplification of the Ross procedure, care must be taken when extrapolating the conclusions to the valve structures.

In tables 5 to 13 , it is noticeable that several parameters tend to go to their limit in the parameter fitting procedure. Most often the structural parameters $\alpha$, expressing the orientation of the fibers, and $\kappa$, expressing the dispersion of the fibers, reach their limit values. This can be attributed to the homogenization of the different layers in the fitting process.

The alignment of the fibers differs in the separate arterial layers. The collagen fibers in the media are closely aligned to the circumferential direction, which corresponds to an $\alpha$ equal to $\pi / 2$, whereas in the intima and adventitia the collagen fibers are more dispersed. This different alignment may lead to difficulties in fitting this parameter. A similar conclusion was drawn by Haskett et al. who found that the measured fiber angle did not correspond to the fitted fiber angle of the GOH model [34]. Performing a fitting which corrects for the inhomogeneity caused by the rakes, as proposed by Fehervary et al. [35], and in which the different layers are considered, e.g. Badel et al. 36] might circumvent the above problem.

Also, the intima, of which the mechanical contribution can be neglected in healthy subjects, might have significant mechanical properties due to intimal hyperplasia as a result of the surgery. This intimal hyperplasia was noticed by Nappi et al., after they performed similar experiments in which they placed a pulmonary autograft in aortic position in growing lambs [16].

This study is limited to evaluating the material properties of the different tissues at two time points. In order to capture the growth and remodeling processes, more time points should be included. This can be done by taking 4D images, e.g. CT or MRI, at several time points, which can also be used to estimate material properties 38 .

Finally, linking mechanical experiments on these tissues to corresponding histo- 
logical findings, should result in considerable insight regarding the growth and remodeling processes, as well as in the incorporation of the PEARS material in

the arterial wall. A more extensive histological evaluation would undoubtedly bring further insights, for which we refer to Vanderveken et al. [27.

\section{Conclusion}

The Ross procedure is a surgery in which the aortic valve is replaced by the patient's own pulmonary valve. However, due to possible dilatation of the pulmonary autograft, the use of this procedure is limited. In this study, we tested a new exostent for the pulmonary autograft in an ovine model. Several tissue types were obtained and mechanically tested.

Normal pulmonary artery has a lower slope in the low strain regions of its stressstrain curves compared to normal aorta. However, rapid stiffening takes place at lower strain levels in pulmonary artery. When placing the pulmonary artery in aortic position, its mechanical behavior changes towards more aorta-like behavior, though this result could not be proven statistically. Finally, adding the exostent around the autograft changes the behavior of the composite material severely as opposed to the baseline behavior. The stiffening effect becomes even more outspoken in the tissue samples with the exostent.

\section{Acknowledgments}

This work was supported by a doctoral grant strategic basic research (SB 1S35316N) and a postdoctoral fellowship (PDO/012) of the Research Foundation Flanders (FWO). The authors would like to thank Maxim Van den Abbeele and Tine Dijkmans for their help with performing the mechanical experiments. The discussions with Marija Smoljkić were imperative for bringing the mechanical analysis to a good end. Finally, we would like to express our gratitude to Mieke Ginckels, Nina Vanden Driessche, and David Célis, for their indispensable help during the animal experiments. 


\section{References}

[1] J. J. M. Takkenberg, L. M. A. Klieverik, P. H. Schoof, R.-j. V. Suylen, L. A. V. Herwerden, P. E. Zondervan, M. H. Yacoub, A. J. J. C. Bogers, The Ross Procedure - A Systematic Review and Meta-Analysis, Circulation 119 (2009) 222-228. doi:10.1161/CIRCULATIONAHA.107.726349.

[2] R. M. Ungerleider, Y. Ootaki, I. Shen, K. F. Welke, Modified Ross Procedure to Prevent Autograft Dilatation, The Annals of Thoracic Surgery 90 (3) (2010) 1035-1037. doi:10.1016/j.athoracsur.2009.09.078 URL http://dx.doi.org/10.1016/j.athoracsur.2009.09.078

[3] E. I. Charitos, T. Hanke, U. Stierle, D. R. Robinson, A. J. J. C. Bogers, W. Hemmer, M. Bechtel, M. Misfeld, A. Gorski, J. O. Boehm, J. G. Rein, C. A. Botha, R. Lange, J. Hoerer, A. Moritz, T. Wahlers, U. F. W. Franke, M. Breuer, K. Ferrari-Kuehne, R. Hetzer, M. Huebler, G. Ziemer, J. J. M. Takkenberg, H. H. Sievers, Autograft Reinforcement to Preserve Autograft Function After the Ross Procedure - A Report From the German-Dutch Ross Registry, Circulation 120 (2009) S146-S155. doi: 10.1161/CIRCULATIONAHA. 108.843391 .

[4] P. H. Schoof, M. G. Hazekamp, G. K. Van Wermeskerken, E. De Heer, J. A. Bruijn, A. C. Gittenberger-de Groot, H. A. Huysmans, Disproportionate enlargement of the pulmonary autograft in the aortic position in growing pig, Journal of Thoracic and Cardiovascular Surgery 115 (6) (1998) 12641272.

[5] P. H. Schoof, J. J. M. Takkenberg, R.-j. Van Suylen, P. E. Zondervan, M. G. Hazekamp, R. A. Dion, B. A. J.J.C., Degeneration of the pulmonary autograft: An explant study, Journal of Thoracic and Cardiovascular Surgery 132 (2006) 1426-1432. doi:10.1016/j.jtcvs.2006.07.035.

[6] E. Rabkin-Aikawa, M. Aikawa, M. Farber, J. R. Kratz, G. Garcia-Cardena, N. T. Kouchoukos, M. B. Mitchell, R. A. Jonas, F. J. Schoen, Clinical 
pulmonary autograft valves: Pathologic evidence of adaptive remodeling in the aortic site, Journal of Thoracic and Cardiovascular Surgery 128 (2004) 552-561. doi:10.1016/j.jtcvs.2004.04.016.

[7] G. S. Carr-White, A. Afoke, E. J. Birks, S. Hughes, A. O'Halloran, S. Glennen, S. Edwards, M. Eastwood, M. H. Yacoub, Aortic Root Characteristics of Human Pulmonary Autografts, Circulation 102 (19 Suppl 3) (2000) III15-22.

[8] A. N. Azadani, S. Chitsaz, P. B. Matthews, N. Jaussaud, J. Leung, A. Wisneski, L. Ge, E. E. Tseng, Biomechanical comparison of human pulmonary and aortic roots, European Journal of Cardio-Thoracic Surgery 41 (2012) 1111-1116. doi:10.1093/ejcts/ezr163.

[9] A. Mookhoek, K. Krishnan, S. Chitsaz, H. Kuang, L. Ge, P. H. Schoof, A. J. J. C. Bogers, J. J. M. Takkenberg, E. E. Tseng, Biomechanics of Failed Pulmonary Autografts Compared to Native Aortic Roots, The Annals of Thoracic Surgerydoi:10.1016/j . athoracsur . 2016.08.061.

URL http://dx.doi.org/10.1016/j.athoracsur.2016.08.061

[10] A. Mookhoek, K. Krishnan, S. Chitsaz, H. Kuang, L. Ge, P. H. Schoof, A. J. J. C. Bogers, J. J. M. Takkenberg, E. E. Tseng, Biomechanics of Failed Pulmonary Autografts Compared With Normal Pulmonary Roots, The Annals of Thoracic Surgery 102 (6) (2016) 1996-2002. doi:10.1016/ j.athoracsur.2016.05.010

URL http://dx.doi.org/10.1016/j.athoracsur.2016.05.010

[11] T. Carrel, A. Kadner, Long-Term Clinical and Imaging Follow-Up After Reinforced Pulmonary Autograft Ross Procedure, Seminars in Thoracic and Cardiovascular Surgery: Pediatric Cardiac Surgery Annual 19 (1) (2016) 59-62. doi:10.1053/j.pcsu.2015.11.005.

URL http://dx.doi.org/10.1053/j.pcsu.2015.11.005

[12] R. Gebauer, S. Cerny, A modification of the Ross procedure to prevent 
pulmonary autograft dilatation 36 (2009) 195-197. doi:10.1016/j.ejcts. 2009.03 .009

[13] A. C. Kollar, S. D. Lick, D. M. Palacio, R. F. Johnson, Ross Procedure With a Composite Autograft Using Stretch Gore-Tex Material, Annals of Thoracic Surgery 88 (2009) e34-e36. doi:10.1016/j.athoracsur.2009. 06.117 .

URL http://dx.doi.org/10.1016/j.athoracsur.2009.06.117

[14] F. Nappi, C. Spadaccio, C. Castaldo, F. Di Meglio, D. Nurzynska, S. Montagnani, M. Chello, C. Acar, Reinforcement of the Pulmonary Artery Autograft with a Polyglactin and Polydioxanone Mesh in the Ross Operation: Experimental Study in Growing Lamb, The Journal of Heart Valve Disease 23 (2014) 145-148.

[15] F. Nappi, C. Spadaccio, M. Fraldi, C. Acar, Use of bioresorbable scaffold for neopulmonary artery in simple transposition of great arteries : Tissue engineering moves steps in pediatric cardiac surgery, International Journal of Cardiology 201 (2015) 639-643. doi:10.1016/j.ijcard.2015.08.124 URL http://dx.doi.org/10.1016/j.ijcard.2015.08.124

[16] F. Nappi, C. Spadaccio, P. Fouret, N. Hammoudi, C. Chachques, M. Chello, C. Acar, An experimental model of the Ross operation : Development of resorbable reinforcements for pulmonary autografts, The Journal of Thoracic and Cardiovascular Surgery 149 (4) (2015) 1134-1142. doi: $10.1016 / \mathrm{j} \cdot \mathrm{jtcvs} .2014 .12 .056$.

URL http://dx.doi .org/10.1016/j.jtcvs . 2014.12.056

[17] F. Nappi, A. R. Donato, D. Di Vito, C. Spadaccio, C. Acar, M. Fraldi, Stress-shielding, growth and remodeling of pulmonary artery reinforced with copolymer scaffold and transposed into aortic position, Biomechanics and Modeling in Mechanobiology 15 (5) (2016) 1141-1157. doi:10.1007/ s10237-015-0749-y. 
[18] F. Nappi, C. Spadaccio, M. Fraldi, S. Montagnani, P. Fouret, C. Chachques, A composite semiresorbable armoured scaffold stabilizes pulmonary autograft after the Ross operation : Mr Ross's dream fulfilled, The Journal of Thoracic and Cardiovascular Surgery 151 (1) (2016) 155-164.e1. doi:10.1016/j.jtcvs.2015.09.084. URL http://dx.doi.org/10.1016/j.jtcvs.2015.09.084

[19] J. Pepper, K. M. J. Chan, J. Gavino, T. Golesworthy, R. Mohiaddin, T. Treasure, External aortic root support for Marfan syndrome: early clinical results in the first 20 recipients with a bespoke implant, Journal of the Royal Society of Medicine (2010) 1-6doi:10.1258/jrsm.2010.100070.

[20] T. Treasure, J. J. M. Takkenberg, T. Golesworthy, F. Rega, M. Petrou, U. Rosendahl, R. Mohiaddin, M. Rubens, W. Thornton, B. Lees, J. Pepper, Personalised external aortic root support (PEARS) in Marfan syndrome: analysis of $1 \$ \$ 9$ year outcomes by intention-to-treat in a cohort of the first 30 consecutive patients to receive a novel tissue and valve-conserving procedure, compared with the publ, Heart 100 (12) (2014) 969-975. doi: 10.1136/heartjnl-2013-304913.

[21] J. Pepper, M. Goddard, R. Mohiaddin, T. Treasure, Histology of a Marfan aorta 4,5 years after personalized external aortic root support, European Journal of Cardio-Thoracic Surgery 48 (2015) 502-505. doi: 10.1093/ejcts/ezu415.

[22] P. Verbrugghe, E. Verbeken, J. Pepper, T. Treasure, B. Meyns, B. Meuris, P. Herijgers, F. Rega, External aortic root support: a histological and mechanical study, Interactive CardioVascular and Thoracic Surgery 17 (April) (2013) 334-339. doi:10.1093/icvts/ivt165.

[23] L. Van Hoof, P. Verbrugghe, E. Verbeken, T. Treasure, N. Famaey, B. Meuris, P. Herijgers, F. Rega, External aortic support: histological comparison of low porosity graft material and a macroporous mesh in sheep 
12 months after implantation, Interactive CardioVascular and Thoracic Surgery.

[24] M. S. Sacks, Biaxial Mechanical Evaluation of Planar Biological Materials, Journal of elasticity 61 (2000) 199-246.

[25] D. Bia, R. L. Armentano, J. C. Grignola, D. Craiem, Y. A. Zócalo, F. F. Ginés, J. Levenson, The Vascular Smooth Muscle of Great Arteries: Local Control Site of Arterial Buffering Function?, Revista Espanola de Cardiologia 56 (12) (2003) 1202-1209.

[26] M. Van den Abbeele, M. Smoljkić, H. Fehervary, S. Verleden, N. Famaey, J. Vander Sloten, Characterisation of mechanical properties of human pulmonary and aortic tissue, IFMBE Proceedings 45 (2014) 387-390.

[27] E. Vanderveken, J. Vastmans, T. Verbelen, P. Verbrugghe, N. Famaey, E. Verbeken, T. Treasure, F. Rega, Reinforcement of pulmonary artery autograft with a Personalized External Aortic Root Support: a histological evaluation, In preparation.

[28] T. C. Gasser, R. W. Ogden, G. A. Holzapfel, Hyperelastic modelling of arterial layers with distributed collagen fibre orientations., Journal of the Royal Society, Interface / the Royal Society 3 (6) (2006) 15-35. arXiv: 0312002v1, doi:10.1098/rsif.2005.0073.

[29] G. A. Holzapfel, T. C. Gasser, R. W. Ogden, A new constitutive framework for arterial wall mechanics and a comparative study of material models, Journal of elasticity (2000) 1-48arXiv:A:1010835316564, doi:10.1023/ $\mathrm{A}: 1010835316564$,

URL http://www .springerlink.com/index/Q1185464175U2738.pdf

[30] P. Skacel, J. Bursa, Material parameter identification of arterial wall layers from homogenised stress-strain data. Computer methods in biomechanics and biomedical engineering 14 (1) (2011) 33-41. doi:10.1080/10255842. 
2010.493516

URL http://www.ncbi.nlm.nih.gov/pubmed/21161797

[31] J. Andersson, A General-Purpose Software Framework for Dynamic Optimization, $\mathrm{PhD}$ thesis, Arenberg Doctoral School, KU Leuven, Department of Electrical Engineering (ESAT/SCD) and Optimization in Engineering Center, Kasteelpark Arenberg 10, 3001-Heverlee, Belgium (October 2013).

[32] D. Robertson, D. Cook, Unrealistic statistics: How average constitutive coefficients can produce non-physical results, Journal of the Mechanical Behavior of Biomedical Materials 40 (2014) 234-239. doi:10.1016/j. jmbbm.2014.09.006

[33] D. Leung, S. Glagov, M. Matthews, Elastin and collagen accumulation in rabbit ascending aorta and pulmonary trunk during postnatal growth. Correlation of cellular synthetic response with medial tension., Circulation Research 41 (1977) 316-323.

[34] D. Haskett, G. Johnson, A. Zhou, U. Utzinger, J. Vande, Microstructural and biomechanical alterations of the human aorta as a function of age and location, Biomechanics and Modeling in Mechanobiology 9 (6) (2010) 725736. doi:10.1007/s10237-010-0209-7.

[35] H. Fehervary, M. Smoljkic, J. Vander Sloten, N. Famaey, Planar biaxial testing of soft biological tissue using rakes: A critical analysis of protocol and fitting process, Journal of the Mechanical Behavior of Biomedical Materials 61 (2016) 135-151. doi:10.1016/j.jmbbm.2016.01.011

[36] P. Badel, S. Avril, S. Lessner, M. Sutton, P. Badel, S. Avril, S. Lessner, M. Sutton, Mechanical identification of layer-specific properties of mouse carotid arteries using 3D-DIC and a hyperelastic anisotropic constitutive model, Computer Methods in Biomechanics and Biomedical Engineering 15 (1) (2012) 37-48. doi:10.1080/10255842.2011.586945. 
[37] J. Vastmans, H. Fehervary, M. Smoljkić, J. Vander Sloten, N. Famaey, Determination of layer-specific properties through planar biaxial and uniaxial tensile tests on intact arterial tissue, In preparation.

[38] M. Smoljkić, J. Vander Sloten, P. Segers, N. Famaey, Non-invasive, energybased assessment of patient-specific material properties of arterial tissue, Biomechanics and Modeling in Mechanobiology 14 (5) (2015) 1045-1056. doi:10.1007/s10237-015-0653-5.

[39] Clipart Panda

URL http://www.clipartpanda.com/categories/ lamb-clipart-black-and-white

[40] CellScale Biomaterials Testing, BioTester Biaxial Test System - User Manual. 


\section{Figures and Tables}

Table 1: Details of the sheep, the bottom three sheep are the control sheep. These details include the age at surgery, the number of weeks between surgery and sacrifice, and the maximal diameter of the autograft measured on a CT scan taken before sacrifice. * The control sheep 0321 was only used for histological evaluation, since not sufficient tissue was harvested for mechanical testing.

\begin{tabular}{lcc} 
Sheep & Age implantation [weeks] & Sacrifice [weeks] \\
\hline 0073 & 48.6 & 29.6 \\
0385 & 32.4 & 25.9 \\
0418 & 47.1 & 29.1 \\
0393 & 33 & 26 \\
0434 & 44.6 & 27.9 \\
0091 & 30.1 & 34.9 \\
0320 & 45 & 26.7 \\
\hline 1858 & 35 & 26.7 \\
1983 & 31.6 & 28.7 \\
$0321^{*}$ & 45.1 & 31.1
\end{tabular}

Table 2: The differences between the two protocols, regarding the variable being controlled (either force or displacement), the physiological level of that variable, the prestretch being imposed (either at the beginning of each stretch or at the beginning of each set of 5 stretches), the initial distance between the rakes, and the rate at which the controlled variable was applied.

\begin{tabular}{c|ccccc} 
& Control & $\begin{array}{c}\text { Physiological } \\
\text { level }\end{array}$ & Prestretch & Start position & $\begin{array}{c}\text { Rate } \\
\text { rakes }\end{array}$ \\
\hline P1 & Force & $600 \mathrm{mN}$ & Every, $70 \mathrm{mN}$ & $6 \mathrm{~mm}$ & $0.3 \mathrm{~N} / \mathrm{s}$ \\
P2 & Disp & $6.8 \%$ & First, $70 \mathrm{mN}$ & $6 \mathrm{~mm}$ & $3.4 \% / \mathrm{s}$
\end{tabular}

Table 3: The range of the GOH parameters. $\alpha$ is allowed to vary between 0 and $\pi / 2$ radians, corresponding to the fibers being fully aligned to the longitudinal direction and to the circumferential direction. $\kappa$ varies between 0 and $1 / 3$ where the latter relates to a fully isotropic fiber distribution.

\begin{tabular}{c|ccccc} 
& $C_{10}[\mathrm{MPa}]$ & $k_{1}[\mathrm{MPa}]$ & $k_{2}[-]$ & $\alpha[\mathrm{rad}]$ & $\kappa[-]$ \\
\hline $\min$ & 0 & 0 & 0 & 0 & 0 \\
$\max$ & 10 & 10 & 100 & $\frac{\pi}{2}$ & $\frac{1}{3}$
\end{tabular}


Table 4: The diameters, obtained from the CT scan taken six months after surgery, of the pulmonary artery, the pulmonary autograft, the aorta proximal and distal to the pulmonary autograft. The CT scan of sheep 0434 did not include the proximal aorta.

\begin{tabular}{lcccc} 
Sheep & Pulmonary artery $[\mathrm{mm}]$ & Pulmonary autograft $[\mathrm{mm}]$ & Proximal aorta $[\mathrm{mm}]$ & Distal aorta $[\mathrm{mm}]$ \\
\hline 0073 & 22.72 & 23.02 & 21.45 & 22.25 \\
0385 & 19.66 & 20.86 & 19.45 & 19.32 \\
0418 & 19.35 & 21.29 & 20.14 & 19.63 \\
0393 & 21.01 & 21.66 & 18.98 & 16.79 \\
0434 & 19.12 & 20.99 & - & 17.71 \\
0091 & 24.93 & 21.13 & 20.32 & 19.59 \\
0320 & 16.23 & 22.51 & 19.52 & 19.22 \\
\hline 1858 & 19.37 & 46.45 & 25.85 & 20.03 \\
1983 & 17.57 & 31.08 & 21.04 & 18.58 \\
0321 & 18.59 & 22.24 & 2.73
\end{tabular}

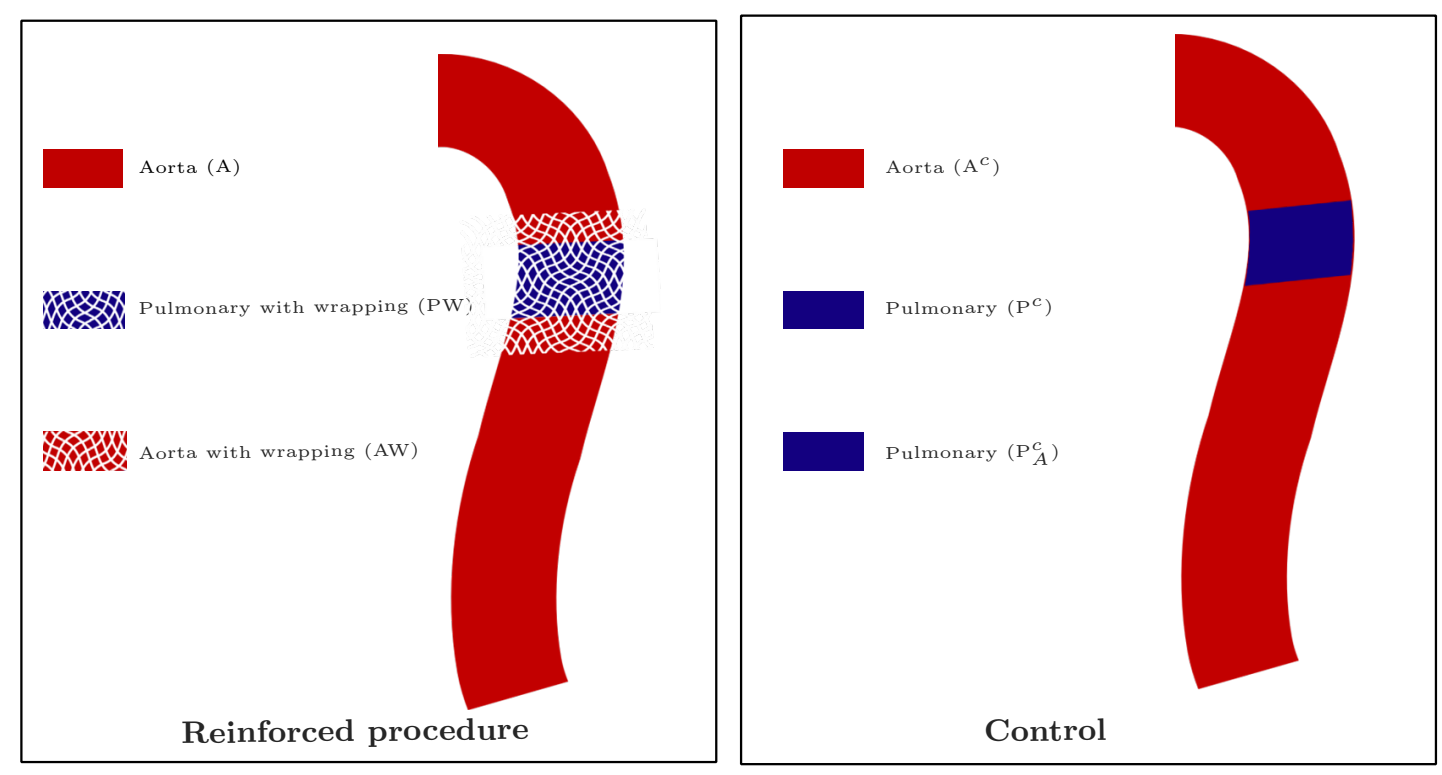

Figure 1: The left figure visualizes the full procedure where part of the thoracic descendens is replaced by a pulmonary autograft, followed by reinforcement with PEARS. The right figure visualizes the control procedure where part of the thoracic descendens is replaced by a pulmonary autograft without subsequent reinforcement 


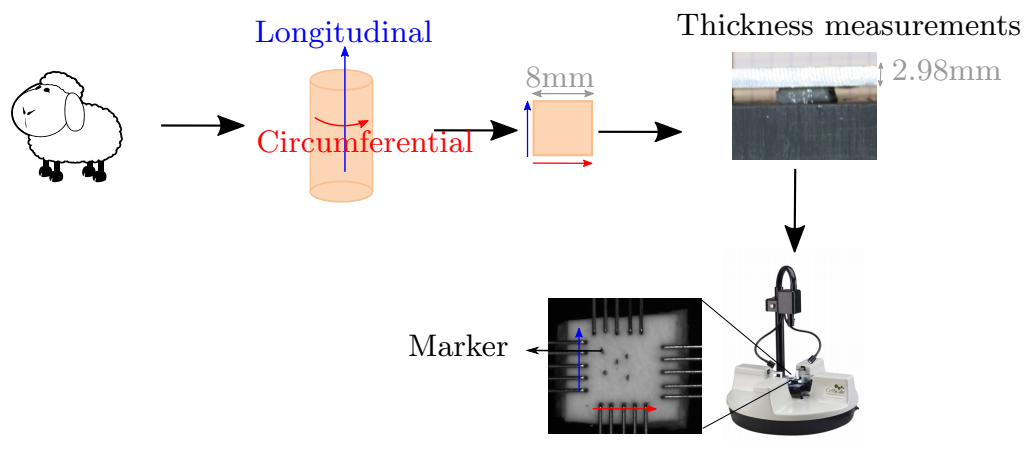

Figure 2: An overview of the different steps in the experimental protocol. A cylindrical sample is excised from the sheep, stored and then prepared into square samples. The thicknesses of these samples were then optically measured, after which biaxial testing is performed. [39, 40]

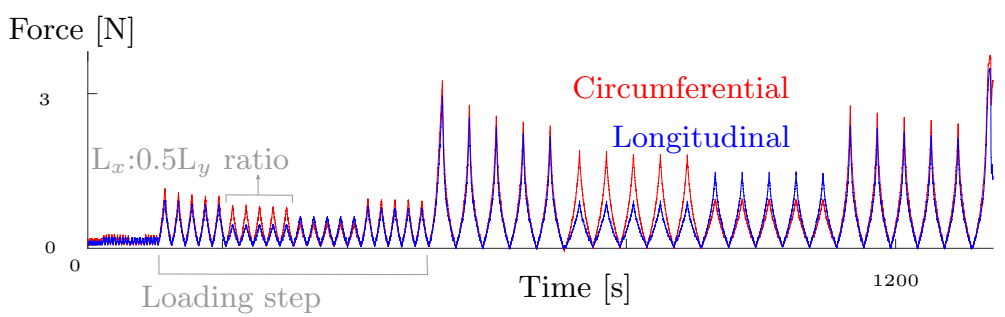

Figure 3: The obtained force curves in circumferential and longitudinal direction after a biaxial test, where the loadingsteps, ratios and stretch-recover cycles are apparent

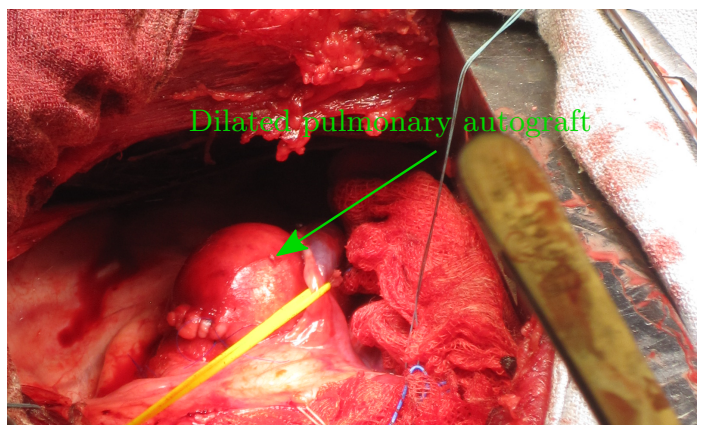

Figure 4: Autograft dilatation is already apparent during surgery. 

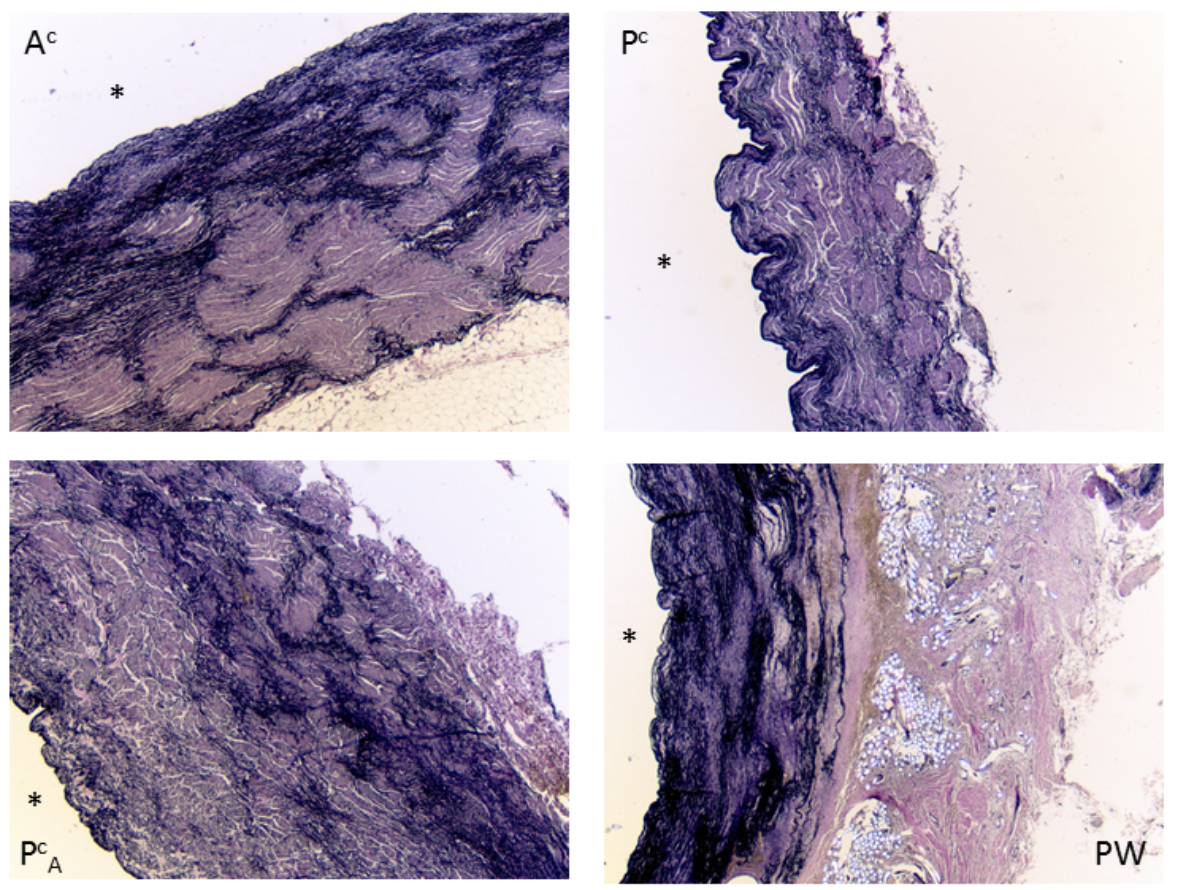

$\overline{500 \mu \mathrm{m}}$

Figure 5: Microscopic visualization using the Elastica van Gieson staining with a 25x magnification. The lumen is marked with *. Elastin is colored in dark purple, smooth muscle cells have a light purple color, and fluid is colored pink. Subfigure A is normal aorta, subfigure $\mathrm{P}^{c}$ is normal pulmonary artery, subfigure $\mathrm{P}_{A}^{c}$ is pulmonary autograft, and subfigure $\mathrm{PW}$ shows the reinforced pulmonary autograft, in which the white spots are the exostent. 

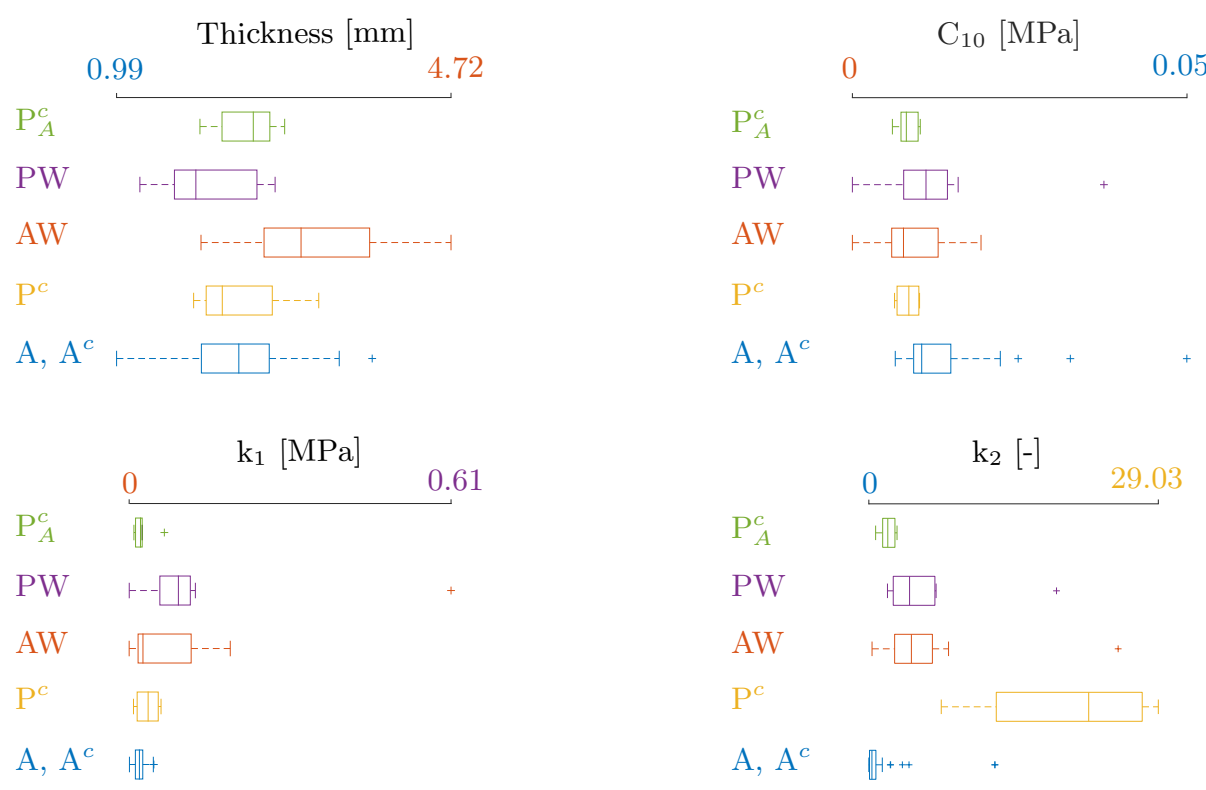

$\mathrm{A}, \mathrm{A}^{c}\left[\mathrm{H}^{+++}+\right.$

Figure 6: Boxplots of the thicknesses, and the material parameters of the GOH model for all tissue types of all sheep.

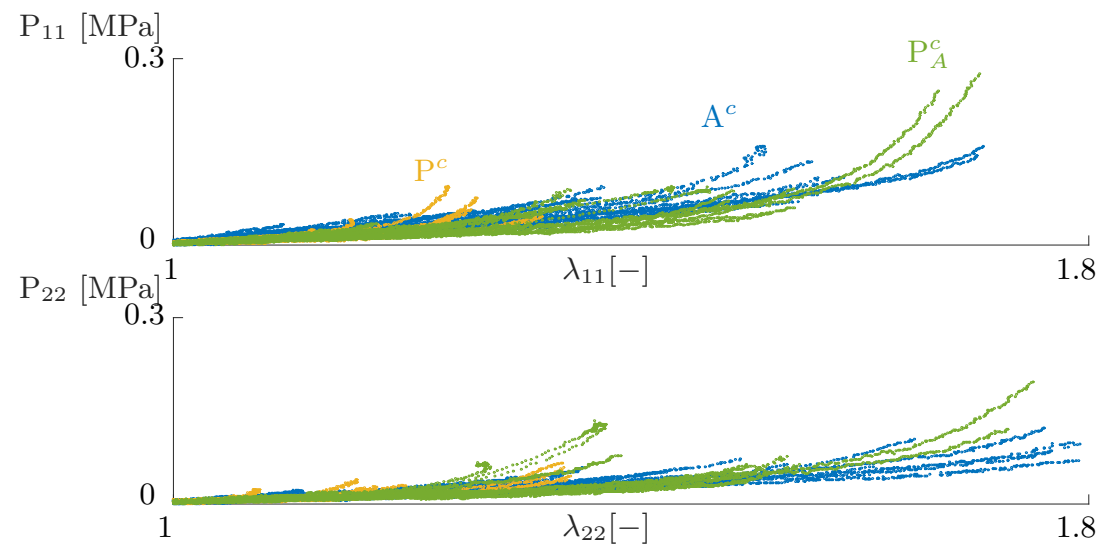

Figure 7: The first Piola-Kirchhoff stress in circumferential (11) and longitudinal (22) direction for the different tissue types of control sheep. The mechanical behavior of normal pulmonary appears to change to aorta like behavior when placed in aortic position for 6 months. 

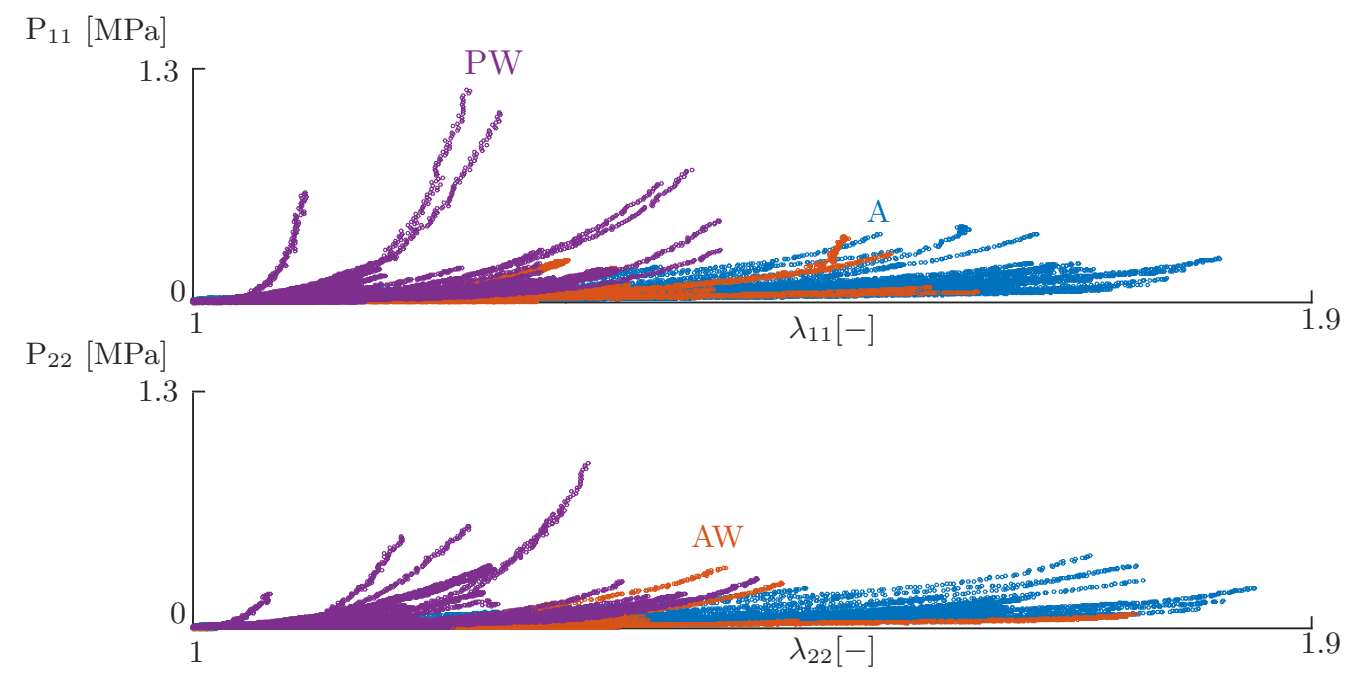

Figure 8: The first Piola-Kirchhoff stress in circumferential (11) and longitudinal (22) direction for the different tissue types of the PEARS sheep. Samples with the PEARS show a more outspoken stiffening effect, compared to their normal counterpart. 


\section{Appendix}

Table 5: Coefficients of constitutive modeling for sheep 0073

\begin{tabular}{|c|c|c|c|c|c|c|c|c|c|}
\hline & $\begin{array}{l}\text { Sample } \\
\text { No }\end{array}$ & Protocol & $\begin{array}{c}\mathrm{C}_{10} \\
{\left[\begin{array}{lll}M & P a\end{array}\right]}\end{array}$ & $\begin{array}{c}\mathrm{k}_{1} \\
{\left[\begin{array}{ll}M & P a\end{array}\right]}\end{array}$ & $\begin{array}{l}\mathrm{k}_{2} \\
{[-]}\end{array}$ & $\begin{array}{c}\alpha \\
{[\mathrm{rad}]}\end{array}$ & $\begin{array}{c}\kappa \\
{[-]}\end{array}$ & $\begin{array}{c}\text { thickness } \\
{[\mathrm{mm}]}\end{array}$ & $\begin{array}{l}R^{2} \\
{[-]}\end{array}$ \\
\hline \multirow{5}{*}{ Aorta } & Sample 1 & $\mathrm{P} 1$ & 0.0305 & 0.0289 & 1.2315 & 1.569 & 0.2764 & 1.3973 & 0.9873 \\
\hline & Sample 2 & P1 & 0.0468 & 0.0468 & 1.35 & 1.5678 & 0.3153 & 1.0817 & 0.9900 \\
\hline & Sample 3 & P2 & 0.0146 & 0.0333 & 0.1688 & 1.5686 & 0.305 & 1.6512 & 0.9644 \\
\hline & Sample 4 & $\mathrm{P} 1$ & 0.0232 & 0.014 & $5.55 e^{-6}$ & 1.2737 & $1.06 e^{-7}$ & 1.928 & 0.1082 \\
\hline & Sample 5 & $\mathrm{P} 2$ & 0.0123 & 0.0458 & 0.2378 & 1.5698 & 0.3025 & 1.7761 & 0.9697 \\
\hline Aorta Wrapped & Sample 1 & $\mathrm{P} 2$ & 0 & 0 & 7.992 & 0.1006 & 0.3212 & 4.7221 & -2.3964 \\
\hline \multirow{3}{*}{ Pulmonary Wrapped } & Sample 1 & $\mathrm{P} 2$ & 0.0148 & 0.1255 & 4.0845 & 0.0002 & 0.2999 & 1.2467 & 0.8993 \\
\hline & Sample2 & $\mathrm{P} 1$ & $1.16 e^{-8}$ & $1.52 e^{-4}$ & 2.5058 & 0.7937 & $3.56 e^{-5}$ & 1.7572 & 0.6828 \\
\hline & Sample3 & P2 & 0.0096 & 0.0734 & 1.8683 & 1.5707 & 0.0929 & 1.3793 & 0.9813 \\
\hline
\end{tabular}

Table 6: Coefficients of constitutive modeling for sheep 0385, * due to hardware problems, this sample was mounted three times

\begin{tabular}{|c|c|c|c|c|c|c|c|c|c|}
\hline & $\begin{array}{l}\text { Sample } \\
\text { No }\end{array}$ & Protocol & $\begin{array}{c}\mathrm{C}_{10} \\
{\left[\begin{array}{lll}M & P a\end{array}\right]}\end{array}$ & $\begin{array}{c}\mathrm{k}_{1} \\
{\left[\begin{array}{ccc}M & P a\end{array}\right]}\end{array}$ & $\begin{array}{l}\mathrm{k}_{2} \\
{[-]}\end{array}$ & $\begin{array}{c}\alpha \\
{[\mathrm{rad}]}\end{array}$ & $\begin{array}{c}\kappa \\
{[-]}\end{array}$ & $\begin{array}{c}\text { thickness } \\
{[\mathrm{mm}]}\end{array}$ & $\begin{array}{l}R^{2} \\
{[-]}\end{array}$ \\
\hline \multirow{6}{*}{ Aorta } & Sample 1 & $\mathrm{P} 1$ & 0.0207 & 0.0067 & 12.6338 & 1.5693 & 0.2119 & 1.874 & 0.9192 \\
\hline & Sample 2 & $\mathrm{P} 1$ & 0.0097 & 0.0207 & 0.8264 & 1.5657 & 0.2396 & 2.5115 & 0.9493 \\
\hline & Sample 3 & P2 & 0.0062 & 0.0227 & 0.0285 & 1.5672 & 0.3221 & 3.1707 & 0.9701 \\
\hline & Sample 4 & P2 & 0.0089 & 0.0253 & 0.2587 & 1.5688 & 0.2987 & 2.2844 & 0.9813 \\
\hline & Sample 5 & $\mathrm{P} 1$ & 0.0129 & 0.0024 & 12.6498 & 1.5679 & 0.1927 & 2.7264 & 0.8978 \\
\hline & Sample 6 & $\mathrm{P} 2$ & 0.0064 & 0.0062 & 3.3626 & 1.5701 & 0.194 & 3.4736 & 0.9515 \\
\hline \multirow{2}{*}{ Aorta Wrapped } & Sample 1 & $\mathrm{P} 1$ & 0.018 & 0.0276 & 25.0024 & 1.5701 & $7.92 e^{-7}$ & 2.6336 & 0.9216 \\
\hline & Sample 2 & $\mathrm{P} 2$ & 0.0039 & 0.1916 & 4.7558 & 1.5706 & 0.2946 & 3.7131 & 0.9503 \\
\hline Pulmonary Wrapped & Sample $1 *$ & P2 & 0.0103 & 0.1127 & 5.4795 & 1.5707 & 0.1983 & 1.7171 & 0.9828 \\
\hline
\end{tabular}

Table 7: Coefficients of constitutive modeling for sheep 0418

\begin{tabular}{|c|c|c|c|c|c|c|c|c|c|}
\hline & $\begin{array}{l}\text { Sample } \\
\text { No }\end{array}$ & Protocol & $\begin{array}{c}\mathrm{C}_{10} \\
{[M P a]}\end{array}$ & $\begin{array}{c}\mathbf{k}_{1} \\
{\left[\begin{array}{lll}M & P a\end{array}\right]}\end{array}$ & $\begin{array}{l}\mathrm{k}_{2} \\
{[-]}\end{array}$ & $\begin{array}{c}\alpha \\
{[\mathrm{rad}]}\end{array}$ & $\begin{array}{c}\kappa \\
{[-]} \\
\end{array}$ & $\begin{array}{c}\text { thickness } \\
{[\mathrm{mm}]}\end{array}$ & $\begin{array}{l}R^{2} \\
{[-]}\end{array}$ \\
\hline \multirow{4}{*}{ Aorta } & Sample 1 & $\mathrm{P} 1$ & 0.0069 & 0.0052 & 0.1585 & 0.8733 & $7.95 e^{-6}$ & 3.4374 & 0.9808 \\
\hline & Sample 2 & P1 & 0.016 & 0.018 & 2.1516 & 1.5686 & 0.3093 & 2.187 & 0.9630 \\
\hline & Sample 3 & $\mathrm{P} 2$ & 0.0093 & 0.0269 & 0.5303 & 1.5681 & 0.2929 & 2.5041 & 0.9822 \\
\hline & Sample 4 & $\mathrm{P} 2$ & 0.0091 & 0.0281 & 0.3094 & 1.5701 & 0.2819 & 2.5152 & 0.9753 \\
\hline Aorta Wrapped & Sample 1 & $\mathrm{P} 2$ & 0.012 & 0.1696 & 2.2527 & 1.5636 & 0.3332 & 1.9294 & 0.9328 \\
\hline Pulmonary Wrapped & Sample 1 & $\mathrm{P} 1$ & $5.12 e^{-4}$ & 0.0988 & 2.6545 & 0.5387 & $4.11 e^{-7}$ & 2.6519 & 0.9015 \\
\hline
\end{tabular}


Table 8: Coefficients of constitutive modeling for sheep 0393

\begin{tabular}{|c|c|c|c|c|c|c|c|c|c|}
\hline & $\begin{array}{l}\text { Sample } \\
\text { No }\end{array}$ & Protocol & $\begin{array}{c}\mathrm{C}_{10} \\
{[\mathrm{MPa}]}\end{array}$ & $\begin{array}{c}\mathrm{k}_{1} \\
{\left[\begin{array}{ccc}M & P & a\end{array}\right]}\end{array}$ & $\begin{array}{l}\mathrm{k}_{2} \\
{[-]}\end{array}$ & $\begin{array}{c}\alpha \\
{[\mathrm{rad}]}\end{array}$ & $\begin{array}{c}\kappa \\
{[-]}\end{array}$ & $\begin{array}{c}\text { thickness } \\
{[\mathrm{mm}]}\end{array}$ & $\begin{array}{l}R^{2} \\
{[-]}\end{array}$ \\
\hline \multirow{5}{*}{ Aorta } & Sample 1 & $\mathrm{P} 2$ & 0.0135 & 0.0303 & 0.469 & 1.5692 & 0.2911 & 1.7213 & 0.9647 \\
\hline & Sample 2 & $\mathrm{P} 1$ & 0.0178 & 0.0276 & 0.6686 & 0.9976 & 0.2119 & 1.8815 & 0.9802 \\
\hline & Sample 3 & $\mathrm{P} 1$ & 0.0196 & 0.0108 & $6.46 e^{-6}$ & 1.2469 & $1.31 e^{-7}$ & 2.3534 & 0.0391 \\
\hline & Sample 4 & $\mathrm{P} 2$ & 0.0083 & 0.0248 & 0.0355 & 1.5678 & 0.2783 & 2.7873 & 0.9684 \\
\hline & Sample 5 & $\mathrm{P} 1$ & 0.0069 & 0.0294 & 0.336 & 1.5697 & 0.2722 & 0.9864 & 0.9247 \\
\hline \multirow{2}{*}{ Aorta Wrapped } & Sample 1 & $\mathrm{P} 1$ & 0.0095 & 0.0247 & 2.3126 & 1.0473 & $4.07 e^{-7}$ & 2.1584 & 0.9937 \\
\hline & Sample 2 & $\mathrm{P} 2$ & 0.007 & 0.1175 & 6.93 & 0.0006 & 0.3217 & 3.8133 & 0.9540 \\
\hline
\end{tabular}

Table 9: Coefficients of constitutive modeling for sheep 0434

\begin{tabular}{|c|c|c|c|c|c|c|c|c|c|}
\hline & $\begin{array}{l}\text { Sample } \\
\text { No } \\
\end{array}$ & Protocol & 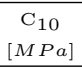 & $\begin{array}{c}\mathrm{k}_{1} \\
{[M P a]}\end{array}$ & $\begin{array}{l}\mathrm{k}_{2} \\
{[-]}\end{array}$ & $\begin{array}{c}\alpha \\
{[\mathrm{rad}]} \\
\end{array}$ & $\begin{array}{c}\kappa \\
{[-]}\end{array}$ & $\begin{array}{c}\text { thickness } \\
{[\mathrm{mm}]}\end{array}$ & $\begin{array}{l}R^{2} \\
{[-]}\end{array}$ \\
\hline \multirow{3}{*}{ Aorta } & Sample 1 & $\mathrm{P} 1$ & 0.0071 & 0.0028 & $4.65 e^{-5}$ & 1.5701 & $5.76 e^{-7}$ & 3.4149 & 0.8725 \\
\hline & Sample 2 & $\mathrm{P} 1$ & 0.0105 & 0.0052 & 0.372 & 1.0009 & $6.25 e^{-9}$ & 2.5347 & 0.9789 \\
\hline & Sample 3 & $\mathrm{P} 2$ & 0.0089 & 0.0215 & $1.98 e^{-6}$ & 1.565 & 0.3243 & 3.8418 & 0.9732 \\
\hline Aorta Wrapped & Sample 1 & $\mathrm{P} 2$ & 0.0073 & 0.032 & 3.952 & 1.5703 & 0.2779 & 3.09 & 0.9731 \\
\hline Pulmonary Wrapped & Sample 1 & P2 & 0.0094 & 0.0933 & 6.5858 & 1.5704 & 0.2514 & 2.4903 & 0.9828 \\
\hline
\end{tabular}

Table 10: Coefficients of constitutive modeling for sheep 0091

\begin{tabular}{|c|c|c|c|c|c|c|c|c|c|}
\hline & $\begin{array}{l}\text { Sample } \\
\text { No }\end{array}$ & Protocol & $\begin{array}{c}\mathrm{C}_{10} \\
{\left[\begin{array}{lll}\mathrm{P} a \\
0\end{array}\right.}\end{array}$ & $\begin{array}{c}\mathrm{k}_{1} \\
{[M P a]}\end{array}$ & $\begin{array}{l}\mathrm{k}_{2} \\
{[-]}\end{array}$ & $\begin{array}{c}\alpha \\
{[\mathrm{rad}]}\end{array}$ & $\begin{array}{c}\kappa \\
{[-]}\end{array}$ & $\begin{array}{c}\text { thickness } \\
{[\mathrm{mm}]}\end{array}$ & $\begin{array}{l}R^{2} \\
{[-]}\end{array}$ \\
\hline \multirow{3}{*}{ Aorta } & Sample 1 & P1 & 0.0087 & 0.019 & 0.1066 & 1.0247 & 0.0617 & 1.9391 & 0.9621 \\
\hline & Sample 2 & $\mathrm{P} 2$ & 0.0095 & 0.0233 & $2.86 e^{-6}$ & 1.57 & 0.2386 & 2.5462 & 0.9730 \\
\hline & Sample 3 & $\mathrm{P} 2$ & 0.0115 & 0.0198 & $4.06 e^{-7}$ & 0.3167 & 0.2274 & 2.2482 & 0.9778 \\
\hline \multirow{2}{*}{ Aorta Wrapped } & Sample 1 & P1 & 0.0143 & 0.0152 & 4.5826 & 1.5698 & $7.81 e^{-7}$ & 2.9763 & 0.9498 \\
\hline & Sample 2 & $\mathrm{P} 2$ & 0.0055 & 0.019 & 2.9208 & 1.5702 & 0.2373 & 3.0039 & 0.9466 \\
\hline \multirow{2}{*}{ Pulmonary Wrapped } & Sample 1 & $\mathrm{P} 2$ & 0.0128 & 0.0782 & 6.7432 & 0.0002 & 0.2545 & 1.872 & 0.9606 \\
\hline & Sample2 & $\mathrm{P} 1$ & 0.0128 & 0.0124 & 2.2748 & 0.8047 & $1.70 e^{-6}$ & 1.7677 & 0.9803 \\
\hline
\end{tabular}

Table 11: Coefficients of constitutive modeling for sheep 0320

\begin{tabular}{|c|c|c|c|c|c|c|c|c|c|}
\hline & $\begin{array}{l}\text { Sample } \\
\text { No }\end{array}$ & Protocol & $\begin{array}{c}\mathrm{C}_{10} \\
{\left[\begin{array}{lll}M & P a\end{array}\right]}\end{array}$ & $\begin{array}{c}\mathrm{k}_{1} \\
{\left[\begin{array}{lll}M & P a\end{array}\right]}\end{array}$ & $\begin{array}{l}\mathrm{k}_{2} \\
{[-]}\end{array}$ & $\begin{array}{c}\alpha \\
{[\mathrm{rad}]}\end{array}$ & $\begin{array}{c}\kappa \\
{[-]}\end{array}$ & $\begin{array}{c}\text { thickness } \\
{[\mathrm{mm}]}\end{array}$ & $\begin{array}{l}R^{2} \\
{[-]}\end{array}$ \\
\hline \multirow{3}{*}{ Aorta } & Sample 1 & $\mathrm{P} 1$ & 0.0149 & 0.0166 & 2.1845 & 1.568 & 0.2527 & 2.6246 & 0.9734 \\
\hline & Sample 2 & P2 & 0.01 & 0.041 & 0.0956 & 1.5688 & 0.3133 & 2.281 & 0.9730 \\
\hline & Sample 3 & $\mathrm{P} 1$ & 0.01 & 0.017 & 0.1512 & 0.917 & $1.50 e^{-6}$ & 1.5266 & 0.9754 \\
\hline Aorta Wrapped & Sample 1 & P2 & 0.007 & 0.0169 & 0.3214 & 1.5676 & 0.2963 & 3.9786 & 0.9653 \\
\hline Pulmonary Wrapped & Sample 1 & $\mathrm{P} 1$ & 0.0352 & 0.61 & 18.821 & 1.5703 & 0.2767 & 2.522 & 0.8947 \\
\hline
\end{tabular}


Table 12: Coefficients of constitutive modeling for control sheep 1858

\begin{tabular}{|c|c|c|c|c|c|c|c|c|c|}
\hline & $\begin{array}{l}\text { Sample } \\
\text { No }\end{array}$ & Protocol & $\begin{array}{c}\mathrm{C}_{10} \\
{\left[\begin{array}{lll}\mathrm{P} a \\
{[}\end{array}\right]}\end{array}$ & $\begin{array}{c}\mathrm{k}_{1} \\
{\left[\begin{array}{ll}M & P a\end{array}\right]}\end{array}$ & $\begin{array}{l}\mathrm{k}_{2} \\
{[-]}\end{array}$ & $\begin{array}{c}\alpha \\
{[\mathrm{rad}]}\end{array}$ & $\begin{array}{c}\kappa \\
{[-]}\end{array}$ & $\begin{array}{c}\text { thickness } \\
{[\mathrm{mm}]}\end{array}$ & $\begin{array}{l}R^{2} \\
{[-]}\end{array}$ \\
\hline \multirow{6}{*}{ Aorta } & Sample 1 & $\mathrm{P} 1$ & 0.015 & 0.0139 & $7.21 e^{-7}$ & 1.3129 & $6.83 e^{-8}$ & 2.3519 & 0.9236 \\
\hline & Sample 2 & P1 & 0.0069 & 0.0104 & 0.3886 & 0.9932 & $6.43 e^{-7}$ & 2.2967 & 0.9745 \\
\hline & Sample 3 & $\mathrm{P} 2$ & 0.0104 & 0.0254 & 0.1306 & 1.5698 & 0.2699 & 1.9356 & 0.9646 \\
\hline & Sample 4 & $\mathrm{P} 2$ & 0.0089 & 0.0225 & 0.0796 & 1.3212 & 0.2433 & 2.0688 & 0.9656 \\
\hline & Sample 5 & $\mathrm{P} 1$ & 0.006 & 0.0151 & 0.2576 & 1.0343 & $4.25 e^{-7}$ & 2.1482 & 0.9430 \\
\hline & Sample 6 & $\mathrm{P} 1$ & 0.0099 & 0.0081 & 0.4995 & 0.9339 & $4.10 e^{-6}$ & 2.1613 & 0.9808 \\
\hline \multirow{2}{*}{ Pulmonary } & Sample 1 & $\mathrm{P} 2$ & 0.0092 & 0.0498 & 29.0313 & 0.7647 & 0.3333 & 2.2068 & 0.8962 \\
\hline & Sample 2 & $\mathrm{P} 1$ & 0.0094 & 0.0221 & 18.2967 & 1.57 & 0.2507 & 1.847 & 0.9638 \\
\hline Pulmonary in AP & Sample 1 & $\mathrm{P} 2$ & 0.0068 & 0.0247 & 2.6176 & 1.57 & 0.2553 & 2.1642 & 0.9166 \\
\hline
\end{tabular}

Table 13: Coefficients of constitutive modeling for sheep 1983

\begin{tabular}{|c|c|c|c|c|c|c|c|c|c|}
\hline & $\begin{array}{l}\text { Sample } \\
\text { No }\end{array}$ & Protocol & 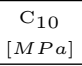 & $\begin{array}{c}\mathrm{k}_{1} \\
{\left[\begin{array}{lll}M P a\end{array}\right]}\end{array}$ & $\begin{array}{l}\mathrm{k}_{2} \\
{[-]}\end{array}$ & $\begin{array}{c}\alpha \\
{[\mathrm{rad}]}\end{array}$ & $\begin{array}{c}\kappa \\
{[-]}\end{array}$ & $\begin{array}{c}\text { thickness } \\
{[\mathrm{mm}]}\end{array}$ & $\begin{array}{l}R^{2} \\
{[-]}\end{array}$ \\
\hline \multirow{6}{*}{ Aorta } & Sample 1 & $\mathrm{P} 2$ & 0.0085 & 0.0151 & 0.4489 & 1.5702 & 0.1835 & 2.6469 & 0.9696 \\
\hline & Sample 2 & $\mathrm{P} 2$ & 0.0096 & 0.0175 & 1.2951 & 1.5701 & 0.2304 & 2.6802 & 0.9637 \\
\hline & Sample 3 & $\mathrm{P} 1$ & 0.0091 & 0.0215 & 0.4496 & 1.5692 & 0.2628 & 2.6702 & 0.9677 \\
\hline & Sample 4 & $\mathrm{P} 2$ & 0.0125 & 0.0206 & 4.0298 & 1.5685 & 0.3047 & 2.7782 & 0.9616 \\
\hline & Sample 5 & $\mathrm{P} 1$ & 0.0086 & 0.0121 & 0.4422 & 1.0876 & 0.1517 & 3.077 & 0.9751 \\
\hline & Sample 6 & $\mathrm{P} 2$ & 0.0072 & 0.0194 & 0.0117 & 1.5693 & 0.2614 & 3.4658 & 0.9569 \\
\hline \multirow{2}{*}{ Pulmonary } & Sample 1 & $\mathrm{P} 2$ & 0.0059 & 0.0604 & 7.262 & 1.5703 & 0.3066 & 2.1276 & 0.8554 \\
\hline & Sample 2 & $\mathrm{P} 1$ & 0.0066 & 0.0082 & 25.8 & 1.5678 & 0.2283 & 3.2446 & 0.8841 \\
\hline \multirow{5}{*}{ Pulmonary in AP } & Sample 1 & P2 & 0.0069 & 0.0099 & 2.827 & 1.5701 & 0.2637 & 2.6984 & 0.9546 \\
\hline & Sample2 & $\mathrm{P} 2$ & 0.0095 & 0.0245 & 0.6802 & 1.5703 & 0.2752 & 1.9176 & 0.8857 \\
\hline & Sample3 & $\mathrm{P} 2$ & 0.0056 & 0.0121 & 2.035 & 1.5695 & 0.2735 & 2.4794 & 0.9591 \\
\hline & Sample4 & $\mathrm{P} 1$ & 0.0092 & 0.0667 & 1.7638 & 0.0003 & 0.2757 & 2.8639 & 0.8657 \\
\hline & Sample5 & $\mathrm{P} 2$ & 0.0082 & 0.0184 & 1.3865 & 1.5687 & 0.3026 & 2.5475 & 0.9738 \\
\hline
\end{tabular}

